\title{
Plasma catecholamine levels and cardiac rhythm before and after cardiac catheterisation
}

\author{
M. B. TURTON, T. DEEGAN, AND N. COULSHED \\ From the Regional Cardiac Centre, Sefton General Hospital, Liverpool
}

Plasma catecholamine concentrations were estimated in a group of 17 fasting patients immediately before and 3 days after cardiac catheterisation. At both times electrocardiograms were recorded and blood pressures, heart rates, and respiration rates measured. Control catecholamine values were established in a group of 10 male and 10 female volunteers, bled at the same time of day under the same conditions of nutrition and posture. Levels of adrenaline and noradrenaline were increased substantially before catheterisation; 3 days later, the values were comparable to those of the control group, though still marginally higher. The increments in catecholamine levels were independent of sex and of the presence or otherwise of persistent supraventricular arrhythmias. In spite of the considerably raised catecholamine levels, electrocardiographic patterns remained unchanged, as did the other physiological values. The absence of any relation between enhanced catecholamine secretion and physiological effects is considered to be the result either of enhanced parasympathetic activity or of adaptation to a prolonged period of stress.

The close links between the sympathoadrenal system and the metabolic consequences of stress have been exemplified by the increased catecholamine excretions observed under different conditions, including apprehension and uncertainty (von Euler, 1964; Frankenhaeuser and Rissler, 1970; Levi, 1970; Konzett et al., 1971; Myager, 1971). Furthermore, in recent years, increased concentrations of plasma catecholamines have been reported during the stressful period immediately after an acute myocardial infarction and attempts have been made to relate these raised levels to the simultaneous presence of cardiac arrhythmias (McDonald et al., 1969; Nelson, 1970; Griffiths and Leung, 1971; Siggers et al., 1971; Lukomsky and Oganov, 1972). The results of these studies have been conflicting or equivocal.

In such circumstances it is possible that evidence for a direct relation between cause and effect was masked by the consequences of either the clinical event or the selective therapy necessarily administered to the patient. These considerations prompted investigation of the possible effects of increased plasma catecholamine concentrations upon cardiac rhythm in subjects who had not suffered a myocardial infarction. This paper describes such a study in a group of patients about to undergo cardiac catheterisation, who had been in an increasingly anxious state for some days. Previous Received for publication 18 April 1977 investigations of the interrelation between stress and arrhythmia promotion in subjects free from acute clinical conditions has been confined to short-term stress situations (Carlson et al., 1968; Taggart et al., 1972, 1973).

\section{Subjects and methods}

\section{SUBJECTS}

The group studied, all of whom had given their informed consent, comprised 17 patients, 6 of whom were male; the mean age was $42 \pm 14$ years. Fourteen subjects had evidence of mitral and/or aortic valve disease and 3 had septal defects (Table 1). None had hepatic, hormonal, renal, or gastrointestinal disorders, and none was receiving drugs or foodstuffs known to influence the metabolism or the estimation of catecholamines.

In addition, control levels of the amines were established in a group of 10 male and 10 female staff members, none of whom was apprehensive of venepuncture. Their mean age was $34 \pm 7$ years.

\section{PROCEDURE}

The patients were admitted to hospital one week before investigation, ate a normal diet, and were allowed light physical activity. Before catheterisation, each subject fasted overnight and immediately before premedication, at $0830 \mathrm{~h}$, blood was withdrawn with minimal stasis from the antecubital 
fossa while resting in a supine position. At the same time, a 60-second bipolar limb lead electrocardiogram was recorded, and blood pressure, heart rate, and respiration rate were measured. Three days later, when the patients had recovered from the catheter investigation and were more relaxed, the procedure was repeated identically.

After an overnight fast, each member of the control group was bled from the same site at the same time of day, $0830 \mathrm{~h}$, after resting in the supine position for at least 15 minutes.

\section{ANALYSES}

All specimens $(20 \mathrm{ml})$ were collected in precooled glass bottles, containing EDTA (20 mg) as anticoagulant and cooled immediately in ice. After centrifugation at $4^{\circ} \mathrm{C}$, plasma was removed and deproteinised by the addition of one-tenth volume of $4 \mathrm{M}$ perchloric acid. The supernatant obtained on further centrifugation was stored at $-18^{\circ} \mathrm{C}$ before analysis. Details of the method for catecholamine separation using Dowex ion exchange resin and subsequent assay by differential spectrophotofluorimetry have been reported previously (Turton and Deegan, 1973).

\section{STATISTICS}

All results are expressed as mean \pm standard deviation; data were analysed by the appropriate Student's $t$ tests with a 5 per cent level of significance.

Table 1 Clinical data

\begin{tabular}{|c|c|c|c|c|}
\hline $\begin{array}{l}\text { Case } \\
\text { No. }\end{array}$ & $\operatorname{Sex}$ & $\begin{array}{l}\text { Age } \\
(y)\end{array}$ & Diagnosis & Rhythm \\
\hline 1 & $\mathbf{F}$ & 16 & Ventricular septal defect & Sinus \\
\hline 2 & $\mathbf{F}$ & 64 & Atrial septal defect & Sinus \\
\hline 3 & $\mathbf{F}$ & 27 & Mitral regurgitation & Sinus \\
\hline 4 & $M$ & 56 & Mitral stenosis & Sinus \\
\hline 5 & $\mathbf{F}$ & 52 & Mitral stenosis & Sinus \\
\hline 6 & $\mathbf{M}$ & 28 & $\begin{array}{l}\text { Aortic stenosis and } \\
\text { regurgitation }\end{array}$ & Sinus \\
\hline 7 & $\mathbf{M}$ & 45 & $\begin{array}{l}\text { Aortic stenosis and } \\
\text { regurgitation }\end{array}$ & Sinus \\
\hline 8 & $\mathbf{M}$ & 37 & Mitral stenosis & Sinus \\
\hline 9 & $\mathbf{M}$ & 58 & Aortic stenosis & Sinus \\
\hline 10 & $M$ & 19 & Atrial septal defect & Atrial flutter \\
\hline 11 & $\mathbf{F}$ & 42 & $\begin{array}{l}\text { Mitral stenosis and } \\
\text { regurgitation }\end{array}$ & Wandering pacemaker \\
\hline 12 & $\mathbf{F}$ & 55 & Mitral stenosis & Atrial fibrillation \\
\hline 13 & $\mathbf{F}$ & 40 & $\begin{array}{l}\text { Mitral stenosis, aortic } \\
\text { and tricuspid } \\
\text { regurgitation }\end{array}$ & Atrial fibrillation \\
\hline 14 & $\mathrm{~F}$ & 45 & $\begin{array}{l}\text { Aortic regurgitation; } \\
\text { mitral stenosis and } \\
\text { regurgitation }\end{array}$ & Atrial fibrillation \\
\hline 15 & $\mathbf{F}$ & 38 & Mitral stenosis & Atrial fibrillation (DK) \\
\hline 16 & $\mathbf{F}$ & 47 & $\begin{array}{l}\text { Tricuspid and mitral } \\
\text { stenosis; mitral } \\
\text { regurgitation }\end{array}$ & Atrial fibrillation (DK) \\
\hline 17 & $\mathbf{F}$ & 46 & Mitral stenosis & Atrial fibrillation (DK) \\
\hline
\end{tabular}

(DK): associated with digoxin and/or hypokalaemia.

\section{Results}

\section{CATECHOLAMINES}

The mean plasma concentrations of both catecholamines before catheterisation were higher than those recorded 3 days later $(P<0.001$, both amines; Table 2). Analyses of the significances of the differences between pairs of individual values supported these findings $(P<0.001$, both amines). The precatheterisation mean values were also much higher than the corresponding control mean concentrations $(P<0.001$, both amines; Table 2$)$ and only 3 patients had levels of both catecholamines below the upper limits of normality of $1.6 \mathrm{nmol} / 1$ for adrenaline and $3.4 \mathrm{nmol} / \mathrm{l}$ for noradrenaline, based upon the respective control mean values +2 SD. Though the postcatheterisation mean values were also higher than the corresponding control values (Table 2), the differences were not significant. Nevertheless, 6 patients still had one or both catecholamine concentrations greater than the respective upper limits of normality.

Male and female patients reacted equally to the stressful situation before catheterisation and had similar mean levels of both catecholamines 3 days later. Though women showed bigger differences between the mean values of the two amines before and after catheterisation, neither effect was significant because of the wide ranges of the differences between pairs of individual values, which resulted in large associated standard deviations for both sexes (Table 2).

The electrocardiograms showed that 9 patients were in sinus rhythm throughout the study. Of

Table 2 Mean levels of plasma catecholamines before and after cardiac catheterisation ( $\mathrm{nmol} / \mathrm{l})$

\begin{tabular}{|c|c|c|c|c|}
\hline Subjects & $n$ & Time & Adrenaline & Noradrenaline \\
\hline All patients & 17 & $\begin{array}{l}\text { Before } \\
\text { After } \\
\text { Difference }\end{array}$ & $\begin{array}{l}4 \cdot 2 \pm 2 \cdot 6 \\
1 \cdot 2 \pm 0 \cdot 8 \\
3 \cdot 0 \pm 2 \cdot 3\end{array}$ & $\begin{array}{l}6 \cdot 8 \pm 3 \cdot 1 \\
2 \cdot 6 \pm 1 \cdot 4 \\
4 \cdot 2 \pm 3 \cdot 4\end{array}$ \\
\hline $\begin{array}{l}\text { Males } \\
\text { Females }\end{array}$ & $\begin{array}{r}6 \\
11\end{array}$ & $\begin{array}{l}\text { Before } \\
\text { After } \\
\text { Difference } \\
\text { Before } \\
\text { After } \\
\text { Difference }\end{array}$ & $\begin{array}{l}3 \cdot 8 \pm 2 \cdot 6 \\
1 \cdot 3 \pm 0.9 \\
2.5 \pm 2 \cdot 2 \\
4 \cdot 4 \pm 2 \cdot 8 \\
1 \cdot 2 \pm 0.9 \\
3 \cdot 2 \pm 2.5\end{array}$ & $\begin{array}{l}6 \cdot 4 \pm 3 \cdot 3 \\
3 \cdot 0 \pm 2 \cdot 0 \\
3 \cdot 4 \pm 4 \cdot 3 \\
7 \cdot 0 \pm 3 \cdot 1 \\
2 \cdot 4 \pm 1 \cdot 0 \\
4 \cdot 6 \pm 3 \cdot 0\end{array}$ \\
\hline $\begin{array}{l}\text { Arrhythmias } \\
\text { Sinus rhythm }\end{array}$ & 8 & $\begin{array}{l}\text { Before } \\
\text { After } \\
\text { Difference } \\
\text { Before } \\
\text { After } \\
\text { Difference }\end{array}$ & $\begin{array}{l}3 \cdot 6 \pm 1 \cdot 9 \\
1 \cdot 3 \pm 0 \cdot 8 \\
2 \cdot 2 \pm 2 \cdot 2 \\
4 \cdot 7 \pm 3 \cdot 2 \\
1 \cdot 1 \pm 0.9 \\
3 \cdot 6 \pm 2 \cdot 4\end{array}$ & $\begin{array}{l}6 \cdot 1 \pm 2 \cdot 8 \\
3 \cdot 1 \pm 1 \cdot 6 \\
3 \cdot 0 \pm 3 \cdot 6 \\
7 \cdot 3 \pm 3 \cdot 4 \\
2 \cdot 2 \pm 1 \cdot 0 \\
5 \cdot 1 \pm 3 \cdot 1\end{array}$ \\
\hline $\begin{array}{l}\text { Normals } \\
\text { Males } \\
\text { Females }\end{array}$ & $\begin{array}{l}20 \\
10 \\
10\end{array}$ & & $\begin{array}{l}0.8 \pm 0.4 \\
0.9 \pm 0.5 \\
0.8 \pm 0.4\end{array}$ & $\begin{array}{l}1.8 \pm 0.8 \\
1.8 \pm 0.7 \\
1.6 \pm 0.8\end{array}$ \\
\hline
\end{tabular}


the rest, 1 patient had atrial flutter, 1 a wandering pacemaker, and 6 were in atrial fibrillation, 3 of whom had RS-T-T wave changes associated with either digitalis therapy or hypokalaemia or both (Table 1). The 8 supraventricular arrhythmias of moderate severity were present in the same form and to the same degree at both times of investigation. No differences were detected between the mean values for either catecholamine in those patients who had arrhythmias and those who were in sinus rhythm, either before or after catheterisation. The apparently larger responses to stress seen in the patients in sinus rhythm were not significant because of the wide ranges of the differences between pairs of individual values, in like manner to the comparable effect in the responses of the male and female patients (Table 2).

\section{PHYSIOLOGICAL DATA}

The mean values for heart rate, respiration rate, and mean diastolic blood pressure before and after catheterisation were almost identical (Table 3) and no significant findings emerged from analyses of the significances of the differences between pairs of individual values in any factor. The physiological data were also independent of the sex of the patients and of the presence or absence of supraventricular arrhythmias.

\section{Discussion}

In common with other stressful conditions, the period of apprehension preceding cardiac catheterisation was accompanied by increased catechola-

Table 3 Mean values of physiological data in patients before and after cardiac catheterisation

\begin{tabular}{|c|c|c|c|c|c|}
\hline Subjects & $n$ & Time & $H R^{\star}$ & $R R^{\star}$ & $M D P \star$ \\
\hline All patients & 17 & $\begin{array}{l}\text { Before } \\
\text { After } \\
\text { Difference }\end{array}$ & $\begin{array}{l}82 \pm 11 \\
86 \pm 11 \\
-4 \pm 11\end{array}$ & $\begin{array}{r}22 \pm 4 \\
22 \pm 3 \\
0 \pm 4\end{array}$ & $\begin{array}{r}98 \pm 9 \\
101 \pm 7 \\
-4 \pm 7\end{array}$ \\
\hline $\begin{array}{l}\text { Males } \\
\text { Females }\end{array}$ & 11 & $\begin{array}{l}\text { Before } \\
\text { After } \\
\text { Difference } \\
\text { Before } \\
\text { After } \\
\text { Difference }\end{array}$ & $\begin{aligned} 81 & \pm 7 \\
81 & \pm 6 \\
0 & \pm 10 \\
81 & \pm 13 \\
89 & \pm 11 \\
-7 & \pm 11\end{aligned}$ & $\begin{aligned} 21 & \pm 4 \\
23 & \pm 3 \\
-2 & \pm 3 \\
23 & \pm 6 \\
21 & \pm 3 \\
1 & \pm 5\end{aligned}$ & $\begin{aligned} 95 & \pm 10 \\
98 & \pm 6 \\
-2 & \pm 5 \\
98 & \pm 9 \\
103 & \pm 8 \\
-5 & \pm 9\end{aligned}$ \\
\hline Sinus rhythm & 8 & $\begin{array}{l}\text { Before } \\
\text { After } \\
\text { Difference } \\
\text { Before } \\
\text { After } \\
\text { Difference }\end{array}$ & $\begin{array}{l}82 \pm 13 \\
84 \pm 13 \\
-2 \pm 13 \\
81 \pm 9 \\
88 \pm 6 \\
-7 \pm 9\end{array}$ & $\begin{aligned} 21 & \pm 5 \\
21 & \pm 4 \\
0 & \pm 4 \\
22 & \pm 6 \\
22 & \pm 3 \\
1 & \pm 5\end{aligned}$ & $\begin{aligned} 100 & \pm 10 \\
104 & \pm 5 \\
-4 & \pm 9 \\
94 & \pm 8 \\
98 & \pm 8 \\
-4 & \pm 7\end{aligned}$ \\
\hline
\end{tabular}

«HR, heart rate (per min); RR, respiration rate (per min); MDP, mean diastolic pressure $(\mathrm{mmHg})$. mine secretion. Plasma concentrations of both adrenaline and noradrenaline were raised considerably with respect to control values established in normal resting volunteers, bled at a similar time of day, and under the same conditions of nutrition and posture. Three days after catheterisation, when the stimulus had disappeared and the patients were less apprehensive, the mean levels of both catecholamines in the two groups were comparable, though the values for the patients were the higher in both cases, and individually, in 6 of the group, exceeded the upper limits of normality for one or both amines. Similar slight increases in mean catecholamine concentrations were also observed in another group of patients admitted for cardiac catheterisation, when they were investigated just before leaving hospital (Turton and Deegan, 1974). Collectively, these findings suggest that admission to hospital per se induces some increase in catecholamine secretion and that allowance should be made for this effect in any investigations of in-patients.

Men and women reacted equally to the stress stimulus and no sex-based differential existed in the levels afterwards or in those of the control group. Previous reports on this aspect have been conflicting; whereas Engelman et al. (1970) found identical responses in male and female members of a group of hypertensive patients, de Quattro and Chan (1972) found higher levels of catecholamines in women in a similar group. However, in both studies, comparable levels were recorded in both sexes in the normal subjects. Throughout the present study, 8 patients had supraventricular arrhythmias. No influence upon plasma catecholamine levels resulting from these persistent abnormalities was observed at any time.

The increased adrenaline and noradrenaline concentrations were not accompanied by any significant changes in mean diastolic pressures, heart rates, or respiration rates. In contrast, when Carlson et al. (1968) exposed subjects intermittently, for periods of 2 hours, to standardised emotional stress of moderate degree, consisting of intense mental activity while being disturbed by flashing lights and noise, increases in heart rate were observed. On the other hand, no increases of systolic or diastolic pressure were detected.

The increased levels of catecholamines before catheterisation were not accompanied by the genesis of cardiac arrhythmias or the modification of the supraventricular arrhythmias. The latter were present in the same form and in the same frequency at a time which may be regarded as a control period, 3 days after the catheter investigation. These observations conflict with reports of electrocardiographic abnormalities and of the 
occurrence of multiple ectopic beats, concomitant with the stress reactions to the intense moist heat of a sauna bath (Taggart et al., 1972) and to public speaking (Taggart et al., 1973), seen in both normal subjects and subjects with coronary artery disease. Under the former conditions, a group of 9 subjects with coronary artery disease had increased heart rates and ST-T segment abnormalities, in the presence of levels of adrenaline $(3.8 \pm 2.6 \mathrm{nmol} / \mathrm{l})$ and noradrenaline $(5.4 \pm 2.0 \mathrm{nmol} / \mathrm{l})$ comparable to those found before catheterisation in the present study. Ventricular ectopic beats were also detected in 4 out of 17 normal subjects, whose mean adrenaline and noradrenaline levels were $1.6 \pm 0.9 \mathrm{nmol} / 1$ and $3.6 \pm 0.8 \mathrm{nmol} / 1$, respectively. Separate information on the values in the subjects in whom arrhythmias were observed was not provided. Increased heart rates and electrocardiographic abnormalities were also evident in a group of 23 normal subjects and in a group of 7 subjects with coronary artery disease, when speaking before an audience. In addition, unspecified increments in plasma noradrenaline levels were reported in 21 normal subjects, when monitored immediately after speaking.

The absence of changes in heart rate and electrocardiographic pattern in the present study is possibly the result of the slower development of the apprehensive state, which produced a more controlled response in catecholamine secretion throughout a longer period than that in the conditions imposed by Carlson et al. (1968) or in either taking a sauna bath (Taggart et al., 1972) or public speaking (Taggart et al., 1973). The relative suddenness of the responses to the latter events produced changes in heart rate, which were not observed under the more gradual conditions of the former. Since, within the limitations of the different techniques used and the incompleteness of the data in some respects, increased catecholamine secretion was a common feature of all the studies, it appears that electrocardiographic abnormalities were more prone to develop when such increased secretion was accompanied by changes in heart rate.

The failure of high adrenaline levels to induce increased heart rates may parallel the observation of Taggart et al. (1976), who reported bradycardia in the presence of increased circulating adrenaline in a group of young women undergoing dental surgery. It was suggested that, in this situation, parasympathetic responses evoked by pain or the expectation of pain predominated over sympathetic responses which would tend to increase the heart rate. Some support for this concept is provided by the physiological data in the present study. Though no significant differences were found between the mean values for heart rate, respiration rate, and mean diastolic pressure before and after catheterisation, 9 of the group had decreased heart rates and 10 had decreased mean diastolic pressures before catheterisation compared with the values afterwards. In addition, at the latter time, when any expectation of pain was absent, the values recorded were consistent with mild sympathetic responses to the concurrent marginal increases in catecholamine secretion.

Alternatively, the overall absence of any physiological responses to raised catecholamine levels may reflect the general adaptation syndrome described by Selye (1946) and may involve a process whereby the secondary effects promoted by a primary increase in plasma concentrations gradually disappear as the subject adapts to the modified situation. Such a view would be consistent with the more prolonged period of stress involved, compared with those of the investigations previously described.

\section{References}

Carlson, L. A., Levi, L., and Crö, L. (1968). Plasma lipids and urinary excretion of catecholamines in man during experimentally induced emotional stress, and their modification by nicotinic acid. Fournal of Clinical Investigation, 47, 1795-1805.

de Quattro, V., and Chan, S. (1972). Raised plasma catecholamines in some patients with primary hypertension. Lancet, 1, 806-809.

Engelman, K., Portnoy, B., and Sjoerdsma, A. (1970). Plasma catecholamine in patients with hypertension. Circulation Research, 26-27, Suppl. 1, 141-145.

Frankenhaeuser, M., and Rissler, A. (1970). Catecholamine output during relaxation and anticipation. Perceptual and Motor Skills, 30, 745-746.

Griffiths, J. C., and Leung, F. (1971). The sequential estimation of plasma catecholamines and whole blood histamine in myocardial infarction. American Heart fournal, 82, 171179.

Konzett, H., Hörtnagl, H., Hörtnagl, H., and Winkler, H. (1971). On the urinary output of vasopressin, epinephrine and norepinephrine during different stress situations. Psychopharmacologia, 21, 247-256.

Levi, L. (1970). Emotional stress and sympathoadrenomedullary and related physiological reactions with particular reference to cardiovascular pathology. In Psychosomatics in Essential Hypertension, p. 38. (Bibliotheca Psychiatrica, No. 144.) Ed. by M. Koster, H. Musaph, and P. Visser. Karger, Basel.

Lukomsky, P. E., and Oganov, R. (1972). Blood plasma catecholamines and their urinary excretion in patients with acute myocardial infarction. American Heart fournal, 83, 182-188.

McDonald, L., Baker, C., Bray, C., McDonald, A., and Restieaux, N. (1969). Plasma catecholamines after cardiac infarction. Lancet, 2, 1021-1023.

Myager, V. (1971). Psychic trauma and cortical-diencephalic interrelationships. In Society, Stress and Disease, vol. 1, p. 258. Ed. by L. Levi. Oxford University Press, London.

Nelson, P. G. (1970). The effect of heparin on serum freefatty acids, plasma catecholamines and the incidence of 
arrhythmias following acute myocardial infarction. British Medical fournal, 3, 735-737.

Selye, H. (1946). The general adaptation syndrome and the diseases of adaptation. Fournal of Clinical Endocrinology, 6 , 117-230.

Siggers, D. C., Slater, C., and Fluck, D. (1971). Serial plasma adrenaline and noradrenaline levels in myocardial infarction using a new double isotope technique. British Heart Fournal, 33, 878-883.

Taggart, P., Carruthers, M., and Somerville, W. (1973). ECG, plasma catecholamines and lipids, and their modification by Oxprenolol when speaking before an audience. Lancet, 2, 341-346.

Taggart, P., Hedworth-Whitty, R., Carruthers, M., and Gordon, P. D. (1976). Observations on electrocardiogram and plasma catecholamines during dental procedures: the forgotten vagus. British Medical fournal, 2, 787-789.
Taggart, P., Parkinson, P., and Carruthers, M. (1972). Cardiac responses to thermal, physical and emotional stress. British Medical fournal, 3, 71-76.

Turton, M. B., and Deegan, T. (1973). Central and peripheral levels of plasma catecholamines, cortisol, insulin and nonesterified fatty acids. Clinica Chimica Acta, 48, 347-352.

Turton, M. B., and Deegan, T. (1974). Circadian variations of plasma catecholamine, cortisol and immuno-reactive insulin concentrations in supine subjects. Clinica Chimica Acta, 55, 389-397.

von Euler, U. S. (1964). Quantitation of stress by catecholamine analysis. Clinical Pharmacology and Therapeutics, 5, 398-404.

Requests for reprints to Dr. M. B. Turton, Regional Cardiac Centre, Sefton General Hospital, Smithdown Road, Liverpool L15 2HE. 